\title{
The biogeochemical cycling of Fe and its isotopes in the South Atlantic Ocean (GEOTRACES GA10)
}

Conway, T. M..$^{1,2}$, Summers, B. A. ${ }^{1}$, SChlosser, C. ${ }^{3}$, SiEBER, M. ${ }^{1}$, JOHN, S. G. ${ }^{4}$, AND ACHTERBERG, E.P. ${ }^{3}$

${ }^{1}$ College of Marine Science, University of South Florida, St Petersburg, FL, USA

${ }^{2}$ School of Geosciences, University of South Florida, St Petersburg, FL, USA.

${ }^{3}$ GEOMAR Helmholtz-Centre for Ocean Research Kiel, 24148 Kiel, Germany

${ }^{4}$ Department of Earth Sciences, University of Southern California, Los Angeles, CA. USA.

*correspondence: tmconway@usf.edu

Iron $(\mathrm{Fe})$ is an essential marine micronutrient, limiting growth of phytoplankton over much of the surface oceans, especially over much of the Southern Ocean. In the last decade, the GEOTRACES program ${ }^{1}$ has provided a wealth of new oceanic Fe data which has illuminated the sources, sinks and cycling of $\mathrm{Fe}$ in the oceans. Fe stable isotopes $\left(\delta^{56} \mathrm{Fe}\right)$ have played an important role in these developments, since they provide insights into the source of the Fe. Here, we present a high-resolution depth transect of dissolved $\mathrm{Fe}$ and $\delta^{56} \mathrm{Fe}$ from a UK GEOTRACES section along $40^{\circ} \mathrm{S}$ in the South Atlantic Ocean (GA10), which sampled South Atlantic gyre waters north of the Subtropical Front in the west, and Southern Ocean waters (south of the Subtropical Front in the east), as well as shallow stations on the South American shelf and slope.

The dissolved Fe GA10 section is dominated by very low concentrations in the surface ocean (as low as $0.03 \mathrm{nM}$ ), typical deep-ocean concentrations of $\sim 0.5 \mathrm{nM}$ in deep waters, and modest point sources of $\mathrm{Fe}(0.8-2 \mathrm{nM})$ associated with both margins and the Mid-Atlantic Ridge ${ }^{1}$. By contrast, and perhaps surprisingly, the dissolved $\delta^{56} \mathrm{Fe}$ section appears to be much more reflective of the vertical water mass structure, with NADW at around $+0.3 \%$ and AAIW/UCDW at $-0.2 \% 0^{2}$, and only limited isotope excursions associated with point sources.

Previously the presence of isotopically light Fe in AAIW has been attributed to regeneration of light Fe at depth ${ }^{3}$. Here, instead, we argue that the isotopically light $\delta^{56} \mathrm{Fe}$ seen in UCDW/AAIW at $40^{\circ} \mathrm{S}$ in the South Atlantic is more consistent with the addition of Fe from shallow sediment or hydrothermal sources either en route from the Southern Ocean, or locally in the South Atlantic, pointing to the importance of these sources for fueling Southern Ocean primary productivity.

References

[1] Schlitzer et al. (2018). Chem. Geol. 493. 210-223.

[2] Conway et al. (2016). Mar. Chem. 183, 50-61.

[3] Abadie et al. (2017). PNAS. 114(5), 858-863. 